\title{
Blucher
}

\author{
Blucher Proceedings \\ Cuba e Brasil no Século XXI (CBS21) \\ Inovação e Desenvolvimento Socioeconômico Sustentável
}

\section{Alagoas: uma visão contemporânea do Sistema Local de Inovação}

Josealdo Tonholo ${ }^{1}$, Eliana Maria de Oliveira Sá², Francisco José Peixoto Rosário, José Francisco Oliveira de Amorim, Kelyane da Silva ${ }^{3}$, Luciana Peixoto Santa Rita, Mônica Melo ${ }^{4}$ Patrícia Brandão Barbosa da Silva, Paula Pradines de

Albuquerque, Reynaldo Rubem Ferreira Junior, Sandra Nunes Leite, Silvia Beatriz Beger Uchoa, Victor Ranieri Bomfim Sampaio de Araújo, João Geraldo de Oliveira Lima ${ }^{5}$

\section{Intróito}

Este texto foi elaborado a partir de uma coletânea de trabalhos do grupo de autores e tem dois propósitos: adensar e atualizar parte do conhecimento relevante acerca do sistema de inovação de Alagoas, e propiciar um melhor conhecimento do Estado e de seus atores em inovação no âmbito do projeto CBS21, que reune cubanos e brasileiros. Por este motivo, vários trechos são compilações dos trabalhos originais que são aqui citados, inclusive com indicação dos sítios para acesso às cópias dos trabalhos. As referências originais, apesar de sua importância para a fundamentação teórica, não serão aqui duplicadas, pois todas estão disponíveis nos trabalhos do grupo.

\footnotetext{
${ }^{1}$ Universidade Federal de Alagoas - UFAL, Maceió, Alagoas. Autor de Referência. E-mail: tonholo@gmail.com. Os demais autores, quando não explicitamente indicada a sua instituição de origem, pertencem também à UFAL.

${ }^{2}$ Federação das Indústrias do Estado de Alagoas - FIEA, UFAL, Faculdade da Cidade de Maceió - FACIMA. www.fiea.org.br/

${ }^{3}$ Instituto de Desenvolvimento Científico e Tecnológico de Alagoas - ICTAL, http://www.ictal.org.br/

${ }^{4}$ Fundação de Amparo à Pesquisa do Estado de Alagoas - FAPEAL, www.fapeal.br/

${ }^{5}$ Centro Universitário CESMAC, Secretaria de Estado de Ciência, Tecnologia e Inovação de Alagoas - SECTI
} 


\section{Introdução}

Em seus mais de 500 anos de história geral e quase 200 anos de existência como Estado, criado como Capitania independente de Pernambuco em 16 de setembro de 1817, Alagoas se desenvolveu com base numa economia assentada na monocultura da cana de açúcar.

Apesar de uma intensa tradição política e riquíssima inserção cultural, que permearam a história do Império e foram determinantes na criação da República, Alagoas sempre teve sua relevância relegada a um segundo plano no país, facilmente constatados pelos atuais baixos índices de desenvolvimento social e participação na economia nacional. Apesar de que o exercício do desenvolvimento pelo viés da inovação ainda é raro, no sentido Schumpteriano do termo ${ }^{6}$, Alagoas tem apresentado um comportamento sui-generis no tocante aos aspectos de gestão da inovação, que aparecem como destaque no cenário nacional: um sistema de inovação que cresce e se fortalece por conta de atores que têm atuação contínua durante quase duas décadas, e são amplamente amparados e respaldados em suas proposições e atuações por suas instituições. Este sistema de inovação, alavancado por $\mathrm{CPF}^{\prime} \mathrm{s}^{7}$, tem se fortalecido ao ponto de transcender situações pontuais de governos e das gestões das instituições participantes, culminando por catalisar uma série de ações positivas que permitem um rápido e efetivo florescimento da prática da inovação no Estado. A partir de um texto suscinto, mas recheado de referências internas e externas de interesse de Alagoas e do tema Sistemas de Inovação, espera-se apresentar a essência do que é atualmente o Sistema Alagoano de Inovação. É este ambiente - emergente, rico e colaborativo - que se pretende apresentar neste capítulo, particularmente aos companheiros cubanos e brasileiros do CBS21, sempre abertos às novas relações e cooperação.

\section{Geografia,Economia e Desenvolvimento Social}

Alagoas é um dos nove Estados que compõem a Região Nordeste do Brasil, contando com 102 municípios, incluindo a capital, Maceió. Segundo o último censo do IBGE o Estado possui uma população de 3.120.494 habitantes, distribuída em

\footnotetext{
${ }^{6} \mathrm{O}$ contexto de Desenvolvimento e Inovação aqui tratado é tratado com base em Schumpeter, que ao elaborar os conceitos básicos de inovação em meados do século $X X$, trata de "desenvolvimento" referindo-se às mudanças da vida econômica que não lhe forem impostas de fora, mas que surjam de dentro, por sua própria iniciativa, ressaltando o seu caráter complexo e dinâmico. Nesse contexto, o processo de desenvolvimento não se restringe ao crescimento econômico e implica em mudança qualitativa da estrutura econômica e social.

${ }^{7}$ Esta terminologia vem da forte relação pessoal do grupo central que atua no Sistema de Inovação de Alagoas, grande parte com mais de 15 anos de história de colaboração. CPF é o código utilizado para Cadastro de Pessoa Física no Brasil, cadastro este único, individual e pessoal.
} 
sua pequena extensão territorial de $27.779,343 \mathrm{Km}^{2}$, o que o eleva à contrastante situação de segundo menor Estado do Brasil, mas o quarto com maior densidade demográfica (112 habitantes $/ \mathrm{km}^{2}$ ). O território de Alagoas apresenta cerca de $230 \mathrm{~km}$ de praias adequadas para banho (cerca de $95 \%$ de sua costa), face ao seu posicionamento primordial na região litorânea, mas ainda conta com 44,36\% de seu território dentro do "polígono das secas", onde o índice de pluviosidade raramente ultrapassa $1000 \mathrm{~mm} /$ ano. Com temperaturas moderadas, apresentando baixa oscilação térmica, ladeado pelo rio São Francisco e portador de várias lagoas, Alagoas tem uma combinação de chuvas, umidade, solos que permitem uma excelente produção agrícola em boa parte do seu território, exceto na região localizada no sertão (menos de $4 \%$ de sua área geográfica).

Como é um Estado famoso por suas belezas naturais, que vão das belas praias, passam pelo agreste e sertão e chegam ao vale do Rio São Francisco, ao longo das últimas décadas, vem atraindo também um grande volume de turistas nacionais e estrangeiros, fazendo com que a participação deste setor na economia aumente consideravelmente.

Pelos dados de 2010 (IBGE, 2010), do ponto de vista da participação no valor bruto da produção industrial do Nordeste, a indústria alagoana representa apenas 3,6\% do Nordeste do Brasil, só à frente do Piauí com 1,6\%. Os dados de 2009 do Ministério do Desenvolvimento, Indústria e Comércio Exterior (MDIC) apontam a relevância das indústrias sucroalcooleira e química, tradicionais commodities de Alagoas, a partir da participação das exportações do Estado no total exportado pela região que é de $7,1 \%$.

Considerando os setores agrário e industrial, a economia gerada a partir da cana de açúcar é consideravelmente majoritária para o Estado. Apesar de que o setor se estruturou a partir de uma economia de base feudal, nota-se um significativo incremento da competitividade do setor, ora chamado sucroenergético, baseado em três itens fundamentais:

1. melhoria dos processos de gestão, inclusive com profissionalização da administração em substituição à antiga estrutura familiar;

2. alteração do regime societário, agora contemplando a participação de capital estrangeiro e;

3. melhoria da qualidade biotecnológica dos cultivares, providos em grande parte pela Universidade Federal de Alagoas (UFAL), através de seu Programa de Melhoramento Genético de Cana de Açúcar (PMGCA) e do conjunto de universidades parceiras da Rede Interuniversitária para o Desenvolvimento do Setor Sucroenergético (RIDESA).

A RIDESA, por meio da UFAL, iniciou parceria com empresas para dar inicio as pesquisas com a finalidade de desenvolver novas variedades RB (abreviação 
de República do Brasil), com capacidade diferenciada de produção de biomassa. Desde 2010 há um árduo trabalho de cruzamentos genéticos no banco de germoplasma da Serra do Ouro (situada no município de Murici, AL) envolvendo espécies de elevado teor de fibra com híbridos de alto rendimento agrícola, visando obtenção de cultivares com características que atendem à produção de etanol de segunda geração (E2G), abraçando novos nichos de mercado. A chegada de novos players no setor sucroenergético e o desenvolvimento de novas tecnologias para etanol de segunda geração propiciarão a melhoria da competitividade do setor no Estado. Dada a importância do setor, a literatura técnica é bastante farta, com destaque para os recentes trabalhos de Rosário et al. (2011 e 2013) que abordam com bastante propriedade a questão da gestão e economia do setor, enquanto Silva et al.(2013) fazem uma análise dos aspectos da inovação gerada a partir do trabalho em biotecnologia do PMGCA da UFAL.

O polo cloroquímico planejado na década de 70, por sua vez, apesar de sua evidente contribuição ao PIB local, baseada na exportação de commodities como cloro, soda e derivados, não obteve o impacto esperado e está em vias de redirecionamento para um polo multifabril. O polo só se tornou operacional graças a uma enorme reserva de sal gema de alta qualidade e de baixo custo de exploração no subsolo da cidade de Maceió e cercanias. Além do sal gema, outro insumo fundamental para este tipo de indústria é a energia elétrica, aqui disponível em abundância, particularmente a partir da usina hidrelétrica de Xingó, localizada na região do sertão, alimentada com águas do Rio São Francisco. Estes dois componentes são cruciais para a competitividade da maior holding do polo, a Braskem (atual detentora da antiga Salgema S/A, empresa que iniciou as atividades). Esse polo hoje tem mais o perfil de abrigo de empresas processadoras de plástico (transformadoras de segunda geração) que de indústria de base, contribuindo com $14 \%$ do PIB estadual.

De outro lado, ao investigar a sintonia dos setores econômicos proeminentes e os que apresentam potencial de desenvolvimento no Estado pela metodologia Delphi, Albuquerque (2012) hierarquizou o sentimento de importância ou de estratégia de um elenco de mais de 100 setores potencialmente interessantes ao Estado, após ouvir mais de 100 atores do sistema de inovação do Estado. O referido trabalho analisou ainda as interações dos atores vinculados à academia, ao governo, aos setores produtivos, bem como o papel das entidades de promoção à inovação na sociedade. No pilar Academia, foram identificadas pesquisas de fronteira em alguns segmentos como de Petróleo, Gás Natural e Petroquímica e Química/Biotecnologia voltadas à Agroindústria Sucroalcooleira. A pesquisa revelou também a possibilidade de um forte descompasso na relação academia-empresa ao evidenciar uma dificuldade em transformar esse conhecimento em produtos, serviços e processos inovadores, criando uma barreira competitiva em seus segmentos produtivos. 
O estudo de Albuquerque (2012) revelou com clareza que as indústrias mais consolidadas são as que apresentam maiores possibilidades de acesso a esses conhecimentos, diferentemente dos setores com menor organização institucional. Esses últimos permanecem menos técnicos e competitivos, o que favorece o aprofundamento do desequilíbrio econômico no Estado. Ainda há que se destacar o papel dos centros de conhecimento, como as universidades, como formadores de mão de obra qualificada.

Com relação aos setores produtivos, Albuquerque identificou como mais significativos para a economia local os setores da agroindústria sucroalcooleira (atualmente autodenominada sucroenergética) e o químico de base (particularmente cloroquímico e de plásticos), uma vez que as demais culturas agroindustriais produzidas não suprem sequer a demanda local, mantendo-se nos moldes da agricultura familiar. Em geral, o Estado apresenta baixa competitividade e diversidade industrial (ALBUQUERQUE, 2012).

Quanto à participação do governo, a percepção dos especialistas pesquisados apontou para um maior impacto das políticas públicas estaduais em relação às federais, ressaltada pela formalização de intermediários no Estado para executarem as estratégias federais, revelando o entendimento de que apenas o repasse de recursos não constitui política de desenvolvimento, sendo necessária a adequação à realidade local. É importante destacar a preocupação inerente a alguns especialistas pesquisados quanto à adequação estratégica das políticas estaduais frente à realidade local e não apenas para acompanhar formalmente as diretrizes nacionais (ALBUQUERQUE, 2012). A partir deste trabalho, alguns direcionamentos estratégicos foram sugeridos, particularmente:

1. aumentar a capilaridade do desenvolvimento em Alagoas, através da interiorização das unidades de ensino, órgãos de apoio e administrativos;

2. prover infraestrutura para o desenvolvimento produtivo, ampliando e modernizando estradas, portos, aeroportos de carga e centros de distribuição;

3. promover a produção agrícola para exportação e não apenas para a subsistência e para atender aos programas de agricultura familiar;

4. direcionar esforços para atender as necessidades básicas da população (saúde, educação e moradia), construindo uma sociedade mais igualitária;

5. capacitar os servidores e empresários para participarem de projetos nacionais;

6. priorizar ações que envolvam mais de um agente de inovação, fortalecendo a comunicação e cooperação entre empresários, acadêmicos e sociedade no desenvolvimento regional e; 
7. induzir a geração de conhecimentos nos setores estratégicos para o Estado (ALBUQUERQUE, 2012).

No aspecto financeiro, a evolução mais explícita do Estado fica evidenciada pela criação, em 2008, da Agência de Fomento de Alagoas (hoje denominada Desenvolve), que tem como papel estratégico coordenar as políticas públicas de fomento e financiamento do Estado. Inclui-se aqui o Programa de Arranjos Produtivos Locais (APL), configurando um avanço do Estado na direção da inclusão financeira a partir da estruturação de um sistema de financiamento público e privado para as MPE, capaz de captar recursos nacionais e internacionais para aplicação na produção local.

Apesar da pujança da economia de alguns setores, Alagoas apresenta indicadores sociais que se sobressaem negativamente, mesmo quando comparado com Estados da mesma região Nordeste: menor IDH (0,722), maior taxa de mortalidade (48,2\%), menor taxa de escolarização de pessoas de 6 a 14 anos (94,6\%), maiores taxas de analfabetismo funcional $(39,0 \%)$ e de analfabetismo $(25,7 \%)$ de pessoas de 15 anos ou mais e até 2003 possuía o maior índice de pobreza da região $(59,54 \%)$.

Reforçando esse contexto, os dados do Ministério do Desenvolvimento Social e Combate à Pobreza (MDS) são taxativos em relação ao elevado grau de dependência da população nordestina dos Programas Sociais do Governo Federal. Segundo as estimativas do MDS os programas de transferência de Renda, assistência social e segurança alimentar injetaram no Nordeste recursos na ordem de $\mathrm{R} \$ 15,7$ bilhões em 2010, beneficiando aproximadamente 38,6 milhões de pessoas, o que corresponde a cerca de $70 \%$ da população da região (SÁ et al., 2011 e LIMA et al., 2011).

Entendendo que o desenvolvimento social perpassa pela competência técnica e competitividade na produção com inovação, é necessário desenvolver todo um aparato de suporte à Ciência e Tecnologia, aspecto do qual Alagoas, como toda região periférica, se ressente, e cuja implementação depende fundamentalmente da capacidade de articulação entre as instituições e organizações públicas e privadas na elaboração e implementação de uma política de CT\&I, capaz de alavancar a geração e difusão de inovações. E aqui se ressalta a importância de um sistema de inovação síncrono, forte e pró-ativo.

\section{Histórico da Ciência, Tecnologia e Inovação (CT\&I)}

Neste tópico serão apresentadas as bases conceituais de sistemas de inovação e de desenvolvimento das instituições e ações de CT\&I em Alagoas, corriqueiramente utilizados nos trabalhos do grupo de autores deste capítulo, como por exemplo, 
Tonholo (2001), Lima et al. (2011), Albuquerque (2012), Santa Rita (2013a), entre outros.

\section{Sobre sistemas nacionais, regionais e locais de inovação}

O recorte "Sistema de Inovação" (SI) começou a se consolidar no final dos anos 80, sobressaindo duas vertentes de interpretações do conceito, ambas abordando os processos de inovação como ação coletiva. Na primeira, Nelson apresenta o SNI com recorte nas relações sistêmicas, amparadas nos esforços de $\mathrm{P} \& \mathrm{D}$ nas empresas e instituições de Ciência e Tecnologia (C\&T) que incluem universidades e políticas públicas de ciência e tecnologia. Por sua vez, Freeman e também Lundvall agregam a esta discussão uma concepção mais ampla de SNI, inserindo o conjunto de instituições que determinam as estratégias das empresas no esforço e desempenho da inovação de um país. Um sistema de inovação reflete o conjunto das várias relações entre instituições de diferentes tipos que, em conjunto e individualmente, contribuem para o desenvolvimento e transmissão de tecnologias, além de ser uma alternativa para as empresas adquirirem novas habilidades e competências. Estão presentes instituições de ensino e pesquisa, financiamento, instituições governamentais, entre outras organizações, além de empresas. Por sua natureza sistêmica, a abordagem de sistemas de inovação põe em foco a inovação e o processo de aprendizado, e pressupõe que desta maneira os atores superam processos deficientes com menos esforços e desperdício de recursos.

As organizações básicas que compõem os sistemas de inovação são as empresas, consideradas o lócus da atividade inovativa; as organizações científicas e tecnológicas, responsáveis pelo desenvolvimento do conhecimento básico e também, pela formação de recursos humanos; as organizações de fomento, que assumem configurações diversas; e o capital empreendedor (venture capital - capital de risco ou de oportunidade), seedmoney - capital semente, business angels - anjos de negócios - investidores de pessoa física).

A abordagem do Sistema de Inovação do Brasil evidencia um conceito que extrapola a tipologia da inovação radical na fronteira tecnológica (leitura de Cassiolato e Lastres) - realizada pelos grandes players internacionais - e reconhece que a inovação vai além das atividades formais de P\&D e "inclui novas formas de produzir bens e serviços, que lhe são novos, independentemente do fato de serem novos, ou não, para os seus competidores - domésticos ou estrangeiros". Este tipo de abordagem revela-se de muita utilidade para os países e regiões com sistemas de inovação poucos sofisticados e maduros. Ao invés de ignorar as especificidades dos diferentes contextos e atores locais, os principais blocos do enfoque em sistemas de inovação exigem que elas sejam captadas e analisadas. A contextualização na análise do processo de aprendizagem e capacitação tem particular importância para países e regiões menos desenvolvidas. 
Por sua vez, o conceito de Sistema Regional de Inovação (SRI) originou-se das discussões a respeito de um sistema nacional de inovação, posto inicialmente por Freeman em 1987, que se caracteriza por tratar a inovação de maneira localizada e evolutiva, levando em consideração os aspectos institucionais e sociais no qual a inovação surge, derivando da relação entre as firmas, instituições de apoio e o entorno institucional local. É aquele "ambiente" no qual as empresas e outras organizações são sistematicamente envolvidas em interações para o aprendizado, por meio de uma rede de cooperação regional institucionalmente construída. Cumpre evidenciar o caráter sistemático que as interações entre as empresas e as outras organizações devem assumir com vistas ao aprendizado e, de outro, a necessidade de uma institucionalização na construção de uma rede de cooperação regional, condição sine qua non para a evolução de um sistema local de inovação (SLI).

A compreensão desse conceito localizado, fica bem explicitado em Rosário et al. (2010): a consideração da pré-existência de trajetórias tecnológicas baseadas em conhecimentos desenvolvidos regionalmente, ou mesmo em conhecimentos gerados fora da região, mas apropriados para a geração e difusão de inovações em âmbito regional.

A infraestrutura para a geração de conhecimento compreende elementos físicos e organizacionais necessários para o apoio à inovação, sendo composto por organizações públicas ou privadas que podem desempenhar papéis diferentes por meio da produção, financiamento, coordenação, supervisão e avaliação da inovação. Nominalmente, essa infraestrutura é composta por universidades, incubadoras de empresas, parques científicos, parques tecnológicos, centros de pesquisa públicos e privados, reguladores da propriedade intelectual e órgãos financiadores da inovação. E todos estes organismos se envolvem na geração e difusão do conhecimento, bem como em seu financiamento e proteção para a apropriabilidade dos benefícios da inovação.

Não menos importante, deve-se considerar também o conjunto de políticas públicas que conduz os incentivos regionais para reforçar a atividade inovadora. As políticas públicas de apoio à inovação são fundamentais para o bom desempenho de um SRI, pois asseguram o aumento da capacidade de aprendizagem e a difusão do conhecimento.

\section{Situação do SLI em Alagoas}

Apesar da ausência de um sistema de métricas que possa aferir os resultados do Estado em inovação, não é de hoje o senso comum de que a cultura da inovação e da proteção intelectual é incipiente e as poucas iniciativas concentram-se, sobretudo, em setores que integram uma economia baseada em commodities, somadas a algumas empresas de base tecnológica (FERREIRA JR. e TONHOLO, 2001). 
De um lado, as fragilidades ressaltadas nas questões sociais do Estado, sobretudo a qualidade da educação, além de impactarem na capacidade inovativa local, comprometem o direcionamento de recursos para áreas que não estejam na linha direta com as urgências sociais.

De outro lado, nota-se que há um claro redirecionamento das ações governamentais que marcaram uma série de transformações fazendo renascer o interesse sobre o papel que o sistema regional de inovação pode ter na reestruturação produtiva, assim como no desenvolvimento da região. Esse interesse coincide com o reconhecimento de sinergias coletivas geradas pela participação dos atores que, efetivamente, fortalecem as chances de inovação e sobrevivência em um mercado sempre mais competitivo. Deve-se também considerar que a economia alagoana, ao tempo em que está associada à produção de base, com baixo conteúdo tecnológico e inovativo, tem apresentado iniciativas na gestão da inovação (ROSÁRIO et al. 2011).

O modelo de governança que se tem estabelecido no território alagoano, caracterizado por décadas de relações informais, tem, paulatinamente, promovido a institucionalização e o gerenciamento de programas de fomento à inovação. Apesar de várias iniciativas relevantes, como um primeiro Plano Estadual de Ciência e Tecnologia, elaborado em 1984, e outra tentativa em 2001, a criação da Fapeal em 1992, a criação da primeira incubadora de Empresas no Estado (Incubal) em 1999, deve-se destacar como marco relevante a própria opção política da criação da Secretaria de Estado de Ciência e Tecnologia (que hoje agrega também o termo Inovação), no ano 2000. Mas o marco recente e mais destacado é a promulgação da Lei Alagoana de Inovação (2009), seguida pelo desenvolvimento coletivo e participativo de um Plano de CT\&I (2013). Estes são indicadores claros dos esforços neste sentido, fruto do trabalho coletivo, que leva à formalização paulatina deste sistema e da opção governamental pelo tema inovação.

Os efeitos produzidos por esta peculiar governança têm se mostrado, até então, fator preponderante de inserção do Estado nas grandes discussões e nos programas nacionais, com clara percepção da importância do tema no âmbito local para a redução das assimetrias locais, regionais e nacionais.

O trabalho de Santa Rita et al. (2013a), elaborado a partir de uma pesquisa com atores de inovação do Estado, mapeou o olhar destes atores sobre os tipos de instituições que estariam envolvidos com a inovação de Alagoas: as Empresas de Base Tecnológica, os Arranjos Produtivos Locais, os Grupos de Pesquisa das Universidades e Centros Tecnológicos, o Sistema $S^{8}$, o Núcleo de Inovação Tecnológica,

\footnotetext{
${ }^{8} \mathrm{O}$ Sistema "S" é formado por organizações criadas pelos setores produtivos (indústria, comércio, agricultura, transportes e cooperativas) com a finalidade de qualificar e promover o bem-estar social de seus trabalhadores. Ao Sistema Indústria, liderado nacionalmente pela Confederação Nacional da Indústria - CNI, são subordinados o Senai - a quem cabe a educação profissional e a prestação de serviços de assistência técnica e tecnológica às empresas industriais; o Sesi que promove a melhoria
} 
as Incubadoras de Empresas, os Órgãos de Fomento e as Instituições Públicas.

Este mesmo trabalho analisou a opinião dos atores acerca das interações institucionais no Estado, em favor da causa da inovação. A percepção geral destes respondentes é pela aparente inexistência de uma rede entre as instituições para o desenvolvimento da inovação em Alagoas. Pode-se verificar que, na percepção dos atores, há reduzido dispêndio de investimentos em Ciência e Tecnologia, bem como em ações que permitam o fomento de projetos inovadores e a formação de recursos humanos.

Por outro lado, esta mesma pesquisa evidencia a percepção de que há forte interação destes agentes com as instituições de ensino, organizações públicas e Sistema S. Além destas, os atores também interagem com instituições financeiras, empresas de base tecnológica e órgãos de fomento. Ademais, as universidades e centros tecnológicos são considerados os principais responsáveis pelo desenvolvimento da inovação. Todavia, apenas $34 \%$ dos entrevistados alegaram que desenvolveram inovações nos últimos 02 anos (SANTA RITA, 2013a).

Do ponto de vista dos objetivos específicos, a pesquisa revelou que as interações mais fortes ocorrem com as universidades e centros de pesquisa, Sistema S, órgãos de fomento, instituições financeiras e instituições públicas, explicitando quase a totalidade interações com o SRI.

Em síntese, foi verificado que as principais fontes de informações para a inovação advêm das Universidades ou dos Centros Tecnológicos. Percebe-se que as inovações de produtos e gestão encontram barreiras frente à necessidade de maior interação entre as empresas e as demais organizações (SANTA RITA, 2013a).

Os dados permitem aferir que o sistema regional de inovação do Estado possui potencial para crescimento e desenvolvimento a partir da diversidade de agentes, condição verificada a partir das interações que de fato ocorrem e são remarcadamente observadas.

Em um trabalho de 2011, Sá et al. descrevem as interações entre as mais proeminentes instituições ativas no sistema de inovação de Alagoas, a partir da métrica de participação destas em alguma das 15 iniciativas/atividades que ocorreram no período de 2008 a 2010 e que foram consideradas mais impactantes na formação de uma cultura favorável à inovação. Procedeu-se ao levantamento das instituições que participaram formalmente de cada atividade, independente da intensidade da participação, classificando-as em cinco grupos:

da qualidade de vida do trabalhador e de seus dependentes por meio de ações em educação, saúde e lazer; e o IEL que promove o desenvolvimento da indústria através da capacitação empresarial e do apoio à pesquisa e à inovação tecnológica. Além disso, pertencem também ao Sistema "S": o Senac Serviço Nacional de Aprendizagem Comercial; o Sesc - Serviço Social do Comércio; o Senar - Serviço Nacional de Aprendizagem Rural; o Senat - Serviço Nacional de Aprendizagem em Transportes; o Sest - Serviço Social de Transportes; o Sebrae - Serviço Brasileiro de Apoio às Pequenas e Médias Empresas; e o Sescoop - Serviço Nacional de Aprendizagem do Cooperativismo. 
1. Sistema Governamental do Estado de Alagoas, diretamente ligado ao Executivo local (tiveram denotada participação: Secretaria de Planejamento e Desenvolvimento do Estado de Alagoas (SEPLAN), Secretaria de Desenvolvimento Econômico do Estado de Alagoas (SEDEC), Secretaria de Ciência, Tecnologia e Inovação do Estado de Alagoas (SECTI), Fundação de Amparo à Pesquisa de Alagoas (FAPEAL), Agência de Fomento de Alagoas (AFAL) agora denominada Desenvolve-AL;

2. Sistema de Apoio Local, com entidades do "Sistema S"e assemelhadas Serviço de Apoio à Pequena e Microempresa de Alagoas (SEBRAE/AL) , Federação das Indústrias do Estado de Alagoas (FIEA), Rede Metrológica de Alagoas (RMAL), Rede Alagoana de Incubadoras de Empresas (RAIE);

3. Academia, agrupando universidades e entidades formadoras em nível superior - Universidade do Estado de Alagoas (UNEAL), Universidade Estadual de Ciências da Saúde de Alagoas (UNCISAL), Centro de Estudos Superiores de Maceió (CESMAC), Universidade Federal de Alagoas (UFAL), Instituto Federal de Educação Tecnológica de Alagoas (IFAL);

4. Instituições de apoio ligadas ao Governo Federal: Financiadora de Estudos e Projetos (FINEP), Agência Brasileira de Desenvolvimento Industrial (ABDI), Banco Nacional de Desenvolvimento Econômico e Social (BNDES)) $\mathrm{e}$

5. Instituições de apoio nacional ou internacional: SISTEMA INDÚSTRIA (CNI, SESI, SENAI E IEL), Serviço Nacional de Apoio à Pequena e Micro Empresa (SEBRAE/NA), Agência Espanhola de Cooperação e Desenvolvimento (AECID), Banco Interamericano de Desenvolvimento (BID).

A estas instituições, atribuiu-se um ponto a cada interação formal com a atividade considerada pró-inovativa, considerando as abaixo relacionadas, de destacada importância no período de estudo (SÁ et al., 2011):

1. Programa de Desenvolvimento de Sistemas Regionais de Inovação (SRI): programa piloto que visa fortalecer os sistemas regionais de inovação dos Estados de Minas Gerais, Santa Catarina, Paraíba e Alagoas, tendo como objetivos específicos:

(a) promover a articulação entre os atores do sistema e sua relação com o ambiente empresarial;

(b) promover o desenvolvimento de políticas e programas voltados para a inovação; 
(c) adequar e desenvolver instrumentos de inovação voltados para a empresa e apoiar a sua implementação;

(d) capacitar instituições, empresas e prestadores de serviços para a inovação;

(e) desenvolver instrumentos de avaliação das políticas de inovação.

2. Mobilização Empresarial pela Inovação (MEI): surgido em 2008, é um movimento de empresários e altos executivos das empresas, capitaneados pela CNI, com o desafio de construir uma agenda positiva para a inovação no Brasil.

3. Projeto SIBRATEC/REALEX : tem por finalidade apoiar o desenvolvimento tecnológico das empresas, por meio da extensão e assistência tecnológica, atendendo aos objetivos do Plano de Ação de Ciência, Tecnologia e Inovação para o Desenvolvimento Nacional (Plano CTI 2007-2010) e as prioridades da política industrial nacional.

4. Programa PAPPE Integração (Programa de Apoio à Pesquisa em Empresas): fomentado pela FINEP, destinou recursos de subvenção econômica aos projetos de desenvolvimento de novos produtos, serviços e processos que auxiliassem as empresas a ingressar numa estratégia econômica vencedora por meio da ocupação de novos mercados.

5. Programa Primeira Empresa Inovadora (PRIME): em operação desde o início de 2009, objetivou subsidiar um conjunto de empresas nascentes de alto valor agregado, criando condições para que se consolidassem com sucesso desde a fase inicial de desenvolvimento dos seus empreendimentos. Programa operado com recursos da FINEP.

6. Programa Agentes Locais de Inovação (ALI): tem como finalidade aumentar a competitividade das empresas participantes por meio da promoção da inovação nas empresas que se dá pela difusão de informações sobre possibilidades de inovação e tecnologia, gerando impacto direto na gestão empresarial e na identificação de novos nichos de mercado. Profissionais especializados que realizam visitas nas empresas identificam os gargalos, orientam, buscam soluções e oferecem respostas às demandas surgidas.

7. Programa Bolsas de Iniciação Tecnológica (BITEC): é um programa voltado para Micro e Pequenas Empresas que tem como parceiros o IEL, o SENAI, o SEBRAE e o CNPq, e objetiva transferir conhecimentos gerados nas instituições de ensino diretamente para o setor produtivo. 
8. Rede Alagoana de Incubadoras de Empresas (RAIE): rede informal com atuação regional cujo objetivo é propor e realizar ações conjuntas como capacitações, captação de recursos, compartilhamento de infra-estrutura, etc., beneficiando as incubadoras de empresas alagoanas. Atualmente, a Rede conta com seis incubadoras ativas: Incubal e Núcleo Espaço Gente (sede na UFAL), Iet (com sede na Fejal/Cesmac), Incla (Senai), Unitec (Uncisal) e Incubadora da Cooperativa Pindorama (na cidade de Coruripe).

9. Rede de Propriedade Intelectual: tem o objetivo de disseminar a cultura da inovação tecnológica e formar quadros de gestores de tecnologia e propriedade intelectual em Alagoas. As instituições componentes da Rede se comprometem em cooperar na busca de ações como promoção de cursos e eventos e elaboração de propostas e projetos, e da busca conjunta de soluções facilitadoras com vistas à implantação da cultura da inovação tecnológica no Estado e à proteção do conhecimento e sua subsequente transferência para o setor produtivo.

10. Rede de NIT: é uma rede que integra os Núcleos de Inovação Tecnológica NIT das várias Instituições de Ciência e Tecnologia, criados com a missão de proteger o patrimônio intelectual dessas instituições e promover a transferência dos resultados de pesquisa ao setor empresarial, buscando fortalecer e ampliar sua inserção.

11. Rede Metrológica de Alagoas (RMAL): criada em 2005 para dar suporte às empresas alagoanas nos processos metrológicos, é uma organização formada por laboratórios especializados em calibração e análise em diversas áreas, que visa estimular e melhorar a qualidade da prestação de serviços de ensaio e calibração realizados pelas empresas alagoanas.

12. Rede Nacional de Política Industrial (RENAPI): é uma iniciativa da Agência Brasileira de Desenvolvimento Industrial (ABDI) e tem como objetivos:

(a) aproximar agentes públicos e privados relacionados à inovação e ao desenvolvimento;

(b) difundir os instrumentos da política industrial do Brasil, chamada de Política de Desenvolvimento Produtivo (PDP);

(c) promover capacitação em temas correlatos; e

(d) contribuir para a regionalização da PDP.

13. Edital AFAL/APL: edital de apoio a projetos de desenvolvimento dos arranjos produtivos locais de baixa renda do Estado de Alagoas, objetiva apoiar 
projetos cuja produção ou comercialização de bens e serviços esteja conectada à vocação, potencialidades e habilidades humanas locais, em atividades produtivas na área rural ou urbana.

14. Edital SENAI-SESI de Inovação: objetiva apoiar projetos de inovação tecnológica e social que compreendam o desenvolvimento de produtos, processos e serviços elaborados pelos departamentos regionais, em parceria com empresas do setor industrial.

15. Mobilização e articulação estadual para o Prêmio FINEP de Inovação: foi concebido para reconhecer e divulgar esforços inovadores realizados por empresas, Instituições Científicas e Tecnológicas (ICTs) e inventores brasileiros.

As correlações de participação institucional medidas pelo estudo de Sá et al. (2011) revelam algumas ausências importantes, como as das demais instituições de ensino superior com atuação local, públicas e privadas. Ao mesmo tempo, revelam uma forte dependência de fomento de órgãos federais para promover a ciência, a tecnologia e a inovação no Estado, particularmente da FINEP, com baixa participação financeira líquida do Governo do Estado. E ressalta ainda que, mesmo reconhecendo a importância da priorização de recursos às carências mais prementes da população, como educação básica, saúde e segurança, por exemplo, é legítimo chamar à responsabilidade para a atuação do governo local, enquanto indutor das políticas industriais de CT\&I, de forma cada vez mais incisiva, ocupando um lugar de maior destaque junto às demais instituições líderes na temática da inovação.

Apesar de ainda não reportados nos estudos de Sá et al. (2011), Albquerque (2012) e Santa Rita et al. (2013a), algumas atividades recentes têm transformado profundamente a organicidade do sistema local, permitindo engajamento de mais instituições e com evidente partilhamento de informações e decisões. Tomamos a liberdade de citar aqui algumas destas ações:

- Indicação Geográfica da Própolis Vermelha de Alagoas (PVA): apesar de um modesto setor apícola enraizado no Estado de Alagoas no final da década de 90, as propriedades químico-farmacológicas da PVA ganharam destaque nas bancadas de cientistas brasileiros, face ao interesse despertado por agentes intermediários, particularmente japoneses, que demonstravam claro interesse no monopólio da comercialização deste subproduto da apicultura. Estudos científicos da década de 90 e meados de 2000 revelaram que as própolis oriundas de colméias das regiões litorânea e estuarino-lagunar do Estado de Alagoas pertenciam a um novo grupo, de origem botânica específica, tendo características farmacológicas e nutracêuticas únicas (liderado por LOPEZ). Após quase 4 anos de atividade intensa de colaboração entre as entidades citadas, o INPI outorgou em 17 de agosto de 2012, a Indicação Geográfica - 
Denominação de Origem, para o domínio "Própolis Vermelha e Extrato de Própolis Vermelha", categoria Mista, incluindo a designação do selo "Denominação de Origem - Manguezais de Alagoas". Esta IG/DO foi a segunda aprovada no País e a primeira da região nordeste, permitindo a equipe do sistema local de inovação aprender com o desbravamento deste difícil setor, compulsório para atores em inovação, a indicação geográfica. O selo da IG para Própolis Vermelha dos Manguezais de Alagoas (PVA) é estratégico por possibilitar ao Estado ocupar espaços em mercados cada vez mais exigentes em termos de produtos de qualidade e de reconhecimento de singularidade. Santa Rita et al. (2013-b) registraram a relevância desta ação para o SLI, com destaque para a participação de instituições como Sebrae e UFAL, além de evidenciar a importância do Programa de Arranjos Produtivos Locais, no qual está inserida o segmento da Apicultura. (SANTA RITA, 2013b).

- Criação do ICTAL e do Parque Tecnológico de Alagoas: o Instituto de Desenvolvimento Científico e Tecnológico de Alagoas (ICTAL), teve sua concepção a partir da submissão do projeto de estruturação dos Polos Agroalimentares localizados nas cidades de Arapiraca e Batalha (Projeto Estruturante do Estado de Alagoas à FINEP, elaborado em 2007). Assim, a partir do anseio político, econômico e das entidades parceiras que compõem o Sistema Local de Inovação, é que em 09 de Junho de 2009 foi formalmente constituído o ICTAL. Nascido com o propósito de ser a entidade gestora dos Polos Tecnológicos Agroalimentares, o instituto vem se fortalecendo e buscando uma trajetória de ações e articulações estaduais na promoção e suporte à execução de programas e projetos com o intuito de catalisar e diversificar as potencialidades locais, como entidade de apoio ao SLI. Em 2011 coube ao ICTAL também ser a entidade executora do Programa de Avicultura Familiar (PAF), no qual, a partir da parceria entre os setores público e privado, busca fomentar ações de desenvolvimento regional utilizando técnicas e capacitações nos 18 municípios que fazem parte do programa no Estado. Também em 2011, os Polos Tecnológicos passaram a integrar uma nova conjuntura de ações estratégicas no Estado com a criação do Parque Tecnológico de Alagoas. Assim, o ICTAL teve papel importante nas discussões e na concepção do novo ambiente colaborativo que nascia em Alagoas. Este novo ambiente traz, contudo, uma ampliação de cobertura das atividades de Ciência, Tecnologia e Inovação no Estado. Com a estruturação física dos Polos Tecnológicos Agroalimentares, efetivamente construídos no final de 2013, o ICTAL tem também atuado com o objetivo de promover o empreendedorismo inovador em Alagoas, estimulando a criação e o fortalecimento de empresas e no desenvolvimento de tecnologias geradas para inserção nos mercados nacional e internacional. O ICTAL tem promovido cursos de capacitação, treinamentos 
e suporte empresarial com viés à inovação, numa perspectiva de contribuir para a melhoria da competitividade das empresas, intermediando parcerias, buscando soluções para aumentar o desempenho, tornando-as mais inovadoras, através da integração que combinam, de forma sinérgica e virtuosa, os esforços de CT\&I entre instituições do setor educacional, do setor produtivo privado e os agentes governamentais. A partir da consolidação do Plano Estadual de CT\&I, coube ao ICTAL assumir a função de entidade propositora/gestora do Projeto de Parque Tecnológico de Alagoas, um projeto de Parque Multipolos, inicialmente com presença em Maceió, Marechal Deodoro, Batalha e Arapiraca, com foco setorial específico para as atividades emergentes e consolidadas no Estado, mas particularmente em plástico, tecnologia de informação e comunicação, química fina/biotecnologia e atividades agroalimentares.

- O movimento de startups: em sintonia com uma forte organização setorial iniciada a partir do APL de Tecnologia de Informação (TI) e fortalecido pela perspectiva da criação de um polo de TI, um movimento emergente em Alagoas tem produzido resultados significativos na criação de startups, sobretudo na área das tecnologias da informação e comunicação (TIC), mas também com alguns projetos de setores mais tradicionais como por exemplo na área de eficiência energética. Lideram esse processo duas instituições de ensino - a UFAL (por meio do Instituto de Computação), além do Programa Educação Básica articulada com Educação Profissional (EBEP), concebido no âmbito do Sistema Indústria e operado pelo Sesi e Senai. Deste movimento afloraram projetos que têm se destacado não só nacionalmente como também mundialmente, à exemplo do Hand Talk, um aplicativo na área de inclusão social que traduz sites para a linguagem de libras (língua brasileira de sinais), que ganhou o título de melhor aplicativo de inclusão social do mundo no prêmio World Summit Award Mobile, criado pela Organização das Nações Unidas (ONU) e entregue em Abu Dhabi.

- Interiorização do Sistema de Educação Tecnológico e Superior: apesar de um evidente problema de baixo nível educacional, com o maior percentual de analfabetismo do país, nota-se uma crescente oferta de educação de qualidade e gratuita em nível tecnológico e superior, agora com ampla permeação geográfica, por todo o Estado. Como componente fundamental do desenvolvimento, a educação tecnológica e superior do Estado de Alagoas sempre ficou concentrada na capital, Maceió. Considerando a importância da oferta destas modalidades, a partir de 2006, a Universidade Federal de Alagoas passou por um processo de expansão muito agressivo, abrangendo numa primeira etapa o Campus Arapiraca, com sede na segunda maior cidade do Estado, 
e polos nas cidades de Palmeira dos índios, Viçosa e Penedo, ofertando 16 novas modalidades de graduação e agora também com pós-graduação stricto e lato sensu. Em 2010 foi inaugurado o Campus de Delmiro Gouveia, junto de seu polo de Santana do Ipanema, atendendo à região do agreste e do sertão de Alagoas com mais 8 novos cursos de graduação. Em 2013 houve decisão de expansão das atividades destas unidades da UFAL, com a criação de novos cursos, inclusive o de Medicina, sediado em Arapiraca. No contexto desta expansão, a UFAL aumentou radicalmente sua capacidade de atendimento, passando de 8 mil estudantes em 2003 para mais de 30 mil no ano de 2013. Também houve iniciativas de expansão por parte do Instituto Federal de Educação de Alagoas (IFAL), que hoje se faz presente nos municípios de Arapiraca, Maceió, Maragogi, Marechal Deodoro, Murici, Palmeira dos Índios, Penedo, Piranhas, Santana do Ipanema, São Miguel dos Campos e Satuba, além de ter mais dois polos onde oferta educação a distância. Cabe destacar a importância do IFAL para do Polo Agroalimentar de Batalha, onde deverá assumir o papel de administradora a partir de junho de 2014 . No total são atendidos mais de 11 mil estudantes, cerca de $60 \%$ superior ao ano de 2008.

- O programa Tecnova em Alagoas: o objetivo do Tecnova é criar condições financeiras favoráveis e apoiar a inovação - por meio de recursos de subvenção econômica - para o crescimento rápido de um conjunto significativo de empresas de micro e pequeno porte, com foco no apoio à inovação tecnológica e com o suporte aos parceiros estaduais. No caso de Alagoas, a parceria de instituições como SECTI, FIEA, SEBRAE, Rede de Incubadoras, entre outras, liderados pela FAPEAL, permitiu a alavancagem de cerca de $\mathrm{R} \$ 8$ milhões para aporte às empresas emergentes de base inovadora, a partir de um edital veiculado em meados de 2014 com avaliação em maio deste mesmo ano. Mas destaque-se que não são apenas os recursos finalísticos que importam neste programa. A mobilização anterior ao lançamento do edital previa capacitação aos empreendedores, palestras, cursos, etc., que permitiram o discurso da inovação se propagar de uma forma ímpar por todo o Estado, com sensibilização de vários microeempreendedores, até então condenados ao ostracismo em relação a inovação. Na fase de pré-inscrição a Fapeal observou o preenchimento de mais de uma centena de formulários, o que é um salto indiscutível na mobilização empresarial para o tema.

- O Plano Estadual de Ciência, Tecnologia e Inovação: talvez o grande marco da consciência institucionalizada do tema, o documento norteador das ações governamentais foi elaborado em 2013 pela SECTI-AL, com apoio técnico do Centro de Gestão e Estudos Estratégicos (CGEE) e das instituições financi- 
adoras como a AECID e a FIEA (por meio do Programa de Fortalecimento dos Sistemas Regionais de Inovação), sempre amparado pelas várias instituições do sistema estadual, em um amplo debate do que se deseja para a Ciência, Tecnologia e Inovação. O Plano de CT\&I (2013) tem previsão de abrangência dos próximos 10 anos e aborda vários aspectos, assentados nos seguintes eixos:

- Eixo 1 - Formulação e implementação de uma política estadual de CT\&I para o desenvolvimento sustentável de Alagoas;

- Eixo 2 - Priorização da educação básica como condição fundamental para promover a inovação;

- Eixo 3 - Estruturação do Sistema Estadual de CT\&I;

- Eixo 4 - Ampliação da capacidade local de geração e difusão de conhecimento, pesquisa e inovação;

- Eixo 5 - Indução da cultura do empreendedorismo e da inovação;

- Eixo 6 - Expansão da oferta de conhecimento, tecnologia e de infraestrutura de CT\&I;

- Eixo 7 - Expansão das ações de CT\&I para o aproveitamento de oportunidades em setores da economia visando à inserção de Alagoas no espaço regional, nacional e global.

No documento são apresentados os resultados de uma pesquisa com atores locais, dados econômicos e estatísticos relacionados aos temas abordados e as sugestões e decisões de ações preferenciais, posicionadas em 42 linhas prioritárias.

\section{Considerações Finais}

A despeito de um panorama socioeconômico que impõe urgência na implantação de transformações em sua dura realidade, Alagoas conta com uma gama de atores institucionais cuja missão perpassa a temática da inovação e que, praticamente em sua totalidade, mesmo apresentando intensidades diferentes na adesão e proposição de iniciativas, estão de alguma forma presente no Sistema Estadual de CT\&I. O evidente crescimento recente das quantidades e qualidades das colaborações institucionais, lastreadas em excelentes relações pessoas físicas - já que cerca de duas dúzias de pessoas pró-ativas e são caracterizadas como atores permanentes no ambiente - tem se configurado em um diferencial que permite projetar Alagoas como um novo e inesperado player a ser ouvido e respeitado em fóruns que compõem o palco brasileiro da inovação. 
Com a semente da inovação devidamente plantada, espera-se agora dar escala nas ações, possibilitando aos empreendedores o acesso ao fomento e ao financiamento, gerando negócios novos e melhores. Estes empreendimentos competitivos, geradores de empregos, rendas e arrecadadores de impostos, somados aos serviços básicos de educação, cultura, segurança e saúde providos e promovidos pelo Estado, compõem a base de uma sociedade capitalista justa e inclusiva, que o povo de Alagoas tanto almeja.

\section{Referências Bibliográficas ${ }^{9}$}

ALBUQUERQUE, P.P., Sistema Alagoano de Inovação: Organização institucional necessária para o desenvolvimento. Dissertação de Mestrado, Programa de Pós-Graduação em Economia Aplicada, Universidade Federal de Alagoas, Maceió, 2012.

FERREIRA Jr, R.R; TONHOLO, J. O Sistema Local de Inovação de Alagoas: Potencialidades e Fragilidades. In: TONHOLO, J. (Org.). Gestão em Ciência e Tecnologia. Maceió, EDUFAL, 2001.

LIMA, J.G.O.; FERREIRA Jr, R.R.; TONHOLO, J. Arranjos Institucionais e Governança Pró-Inovação em Regiões Periféricas. In: XIV Congreso ALTEC 2011, Lima.

LUSTOSA, M.C.J.; ROSÁRIO, F.J.P. Desenvolvimento Local em Regiões Periféricas: a política dos arranjos produtivos em Alagoas. Maceió, Edufal, 2011. Plano de CTI-AL-2013 - www.fundepes.br/docs/

ROSÁRIO, F.J.P.; SANTA RITA, L.P.; ALBUQUERQUE, P.P; TONHOLO, J. Organizações, instituições e tecnologia na agroindústria sucroalcooleira: aplicação da abordagem de sistema setorial de inovação. Revista de Economia Mackenzie (Impresso), v. V. 9, p. 119-143, 2011.

ROSÁRIO, F.J.P.; SANTA RITA, L.P.; ALBUQUERQUE, P.P. Technology, Relationship and Support Institutions on Sectoral Systems of Innovation and Production in Brazil's Northwest Bio Ethanol and Sugar Agro-industry. Journal of Technology Management \& Innovation, v. 8, p. 285-303, 2013.

SÁ. E.M.O.; FERREIRA Jr, R.R., SANTA RITA, L.P.; TONHOLO J. Sistema Regional de Inovação: o Caso de Alagoas, In: XIV Congreso ALTEC 2011, Lima.

SANTA RITA, L.P.; SÁ, E.M.O; TONHOLO, J.; FERREIRA Junior, R.R.; AMORIM, J.F. . Sistema Regional de Inovação: agentes e interações no Estado de Alagoas. In: XV Congresso ALTEC 2013, 2013, Porto.

(Santa Rita, 2013 a) SANTA RITA, L.P.; TONHOLO, J.; SÁ, E.M.O.; UCHÔA, S.B.B.; SILVA, P.B.B.; ALBUQUERQUE, P.P.; BENTES, A. Indicação geográfica da própolis vermelha de Alagoas: descrição dos antecedentes no processo da busca

\footnotetext{
${ }^{9}$ Estas referências estão disponíveis em formato PDF no sítio http : //goo.gl/C11W0r.
} 
da proteção no Instituto Nacional de Propriedade Industrial. In: XV Congresso ALTEC 2013, Porto.

(Santa Rita, 2013 b) SILVA, P.B.B.; UCHOA, S.B.B.; TONHOLO, J.; ARAUJO, T.G.L.; FLORENTINO, E.A.P.G.; ARAUJO, V.R.B.S. Prospecção tecnológica das cultivares de cana-de-açúcar da Rede Intrauniversitária para o Desenvolvimento do Setor Sucroenergético-Ridesa.. Cadernos de Prospecção, v. 6, p. 201218, 2013.

SILVA, P. B. B., O Setor Sucroenergético e o regime de apropriabilidade de cultivares de cana-de-acúcar: caso Ridesa Dissertação de Mestrado, Programa de Pós-Graduação em Economia Aplicada, Universidade Federal de Alagoas, Maceió, 2013.

Recife, Olinda, Maceió, 2014 